\title{
Epigenetic silencing of IncRNA MORT in 16 TCGA cancer types
}

\section{[version 1; peer review: 3 approved]}

\author{
Lukas Vrba (iD)1, Bernard W. Futscher 1,2 \\ ${ }^{1}$ The University of Arizona Cancer Center, Tucson, AZ, 85724, USA \\ ${ }^{2}$ Department of Pharmacology \& Toxicology, College of Pharmacy, The University of Arizona, Tucson, AZ, 85724, USA
}

\author{
V1 First published: 21 Feb 2018, 7:211 \\ https://doi.org/10.12688/f1000research.13944.1 \\ Latest published: 21 Feb 2018, 7:211 \\ https://doi.org/10.12688/f1000research.13944.1
}

Open Peer Review

\begin{tabular}{lccc}
\hline Approval Status & 1 & 3 \\
\hline version 1 & & 2 & \\
21 Feb 2018 & view & view & view
\end{tabular}

1. Adam Karpf ID, University of Nebraska

Medical Center, Omaha, USA

2. Gwen Lomberk, Medical College of

Wisconsin, Milwaukee, USA

3. Alexander Dobrovic (D), Olivia Newton-John

Cancer Research Institute, Heidelberg,

Australia

Any reports and responses or comments on the article can be found at the end of the article. 
Corresponding author: Lukas Vrba (Ivrba@uacc.arizona.edu)

Author roles: Vrba L: Conceptualization, Data Curation, Formal Analysis, Investigation, Methodology, Software, Visualization, Writing Original Draft Preparation, Writing - Review \& Editing; Futscher BW: Funding Acquisition, Writing - Review \& Editing

Competing interests: No competing interests were disclosed.

Grant information: This work was supported by the Maynard Chair in Breast Cancer Epigenomics at the University of Arizona Cancer Center and the Cancer Center Support Grant (P30 CA023074).

The funders had no role in study design, data collection and analysis, decision to publish, or preparation of the manuscript.

Copyright: @ 2018 Vrba L and Futscher BW. This is an open access article distributed under the terms of the Creative Commons Attribution License, which permits unrestricted use, distribution, and reproduction in any medium, provided the original work is properly cited.

How to cite this article: Vrba $L$ and Futscher BW. Epigenetic silencing of IncRNA MORT in 16 TCGA cancer types [version 1; peer review: 3 approved] F1000Research 2018, 7:211 https://doi.org/10.12688/f1000research.13944.1

First published: 21 Feb 2018, 7:211 https://doi.org/10.12688/f1000research.13944.1 


\section{Introduction}

MORT was originally found as a transcript silenced during in vitro immortalization of human mammary epithelial cells ${ }^{1}$. Like a significant majority of lncRNAs, MORT's molecular function remains enigmatic. The MORT gene is specific to higher primates, is expressed in all normal human cell types, and MORT RNA is located predominantly in the cytoplasm ${ }^{1}$. Analysis of MORT expression and the DNA methylation state of its promoter in 17 cancer types from The Cancer Genome Atlas (TCGA) $)^{2}$, which represent the 10 most frequent cancers in males and females, showed MORT is epigenetically silenced in 15 of 17 these cancers ${ }^{1}$. Based on the data from the original in vitro study $^{1}$, we predicted epigenetic MORT silencing occurs early in human carcinogenesis and therefore could be seen in premalignant lesions, such as ductal carcinoma in situ of the breast and colonic adenomas. We used data from clinical samples from published genomic data sets $^{3-8}$ to address this possibility, and indeed, MORT loss occurs prior to or at the stage of pre-malignancy and not thereafter ${ }^{9}$. Taken together these facts suggest that MORT transcript has a tumor suppressive role and is not simply an epigenetic "passenger error."

Since our previous analysis of MORT in TCGA datasets was not exhaustive and only reported on 17 out of 33 TCGA cancer types, the goal of this short study was to extend our earlier work and complete the analysis of MORT DNA methylation associated gene silencing in the final 16 TCGA cancer types.

\section{Methods}

We integrated the MORT expression level and the DNA methylation state of its promoter region using TCGA data as described before ${ }^{1}$. The Illumina HiSeq RNA-seq and HumanMethylation450 DNA methylation data for samples of 16 TCGA cancer types listed in Table 1 were downloaded from the GDC data portal. The data were analyzed in the $\mathrm{R}$ programming environment, version 3.4.2 ${ }^{10}$. The mean RNA-Seq rpkm values for the two exons constituting the MORT RNA were plotted against the mean DNA methylation beta value of the $7 \mathrm{CpGs}$ from the $M O R T$ promoter region for the individual samples of each cancer type. The Spearman correlation coefficient rho between the MORT RNA level and the DNA methylation of MORT promoter was calculated using the function cor.test.

\section{Results and discussion}

Seven of sixteen analyzed cancer types (CESC, CHOL, ESCA, MESO, SARC, STAD, and UCS) show strong MORT silencing by DNA methylation (Figure 1). The negative correlation rho between MORT expression and DNA methylation in these cancers is below -0.5; the DNA methylation level in some tumor samples of these cancers exceeds 0.5 beta (> 50\% DNA methylation), and a large fraction of the tumor samples in these cancer types have very low to no MORT expression level (Figure 1). The correlation of MORT expression and promoter DNA methylation in the remaining nine cancer types is also negative; however, the maximum level of the DNA methylation

Table 1. The 16 TCGA cancer types analyzed in this study. The numbers of primary tumor and normal samples for which both the MORT RNA expression and the MORT promoter DNA methylation data were available are listed. *DNA methylation data from HumanMethylation27 platform that covers $2 \mathrm{CpGs}$ out of 7 CpGs covered by HumanMethylation450 were used.

\begin{tabular}{|l|l|l|l|}
\hline TCGA Cancer Type Name & Abbreviation & $\begin{array}{l}\text { Tumor } \\
\text { samples }\end{array}$ & $\begin{array}{l}\text { Normal } \\
\text { samples }\end{array}$ \\
\hline adrenocortical carcinoma & ACC & 79 & 0 \\
\hline $\begin{array}{l}\text { cervical squamous cell carcinoma and } \\
\text { endocervical adenocarcinoma }\end{array}$ & CESC & 304 & 3 \\
\hline cholangiocarcinoma & CHOL & 36 & 9 \\
\hline esophageal carcinoma & ESCA & 184 & 9 \\
\hline glioblastoma multiforme & GBM & 51 & 1 \\
\hline kidney chromophobe & KICH & 66 & 0 \\
\hline brain lower grade glioma & LGG & 516 & 0 \\
\hline mesothelioma & MESO & 87 & 0 \\
\hline ovarian serous cystadenocarcinoma & OV* & 295 & 0 \\
\hline pheochromocytoma and paraganglioma & PCPG & 179 & 3 \\
\hline sarcoma & SARC & 259 & 0 \\
\hline stomach adenocarcinoma & STAD & 373 & 0 \\
\hline testicular germ cell tumors & TGCT & 150 & 0 \\
\hline thymoma & THYM & 120 & 2 \\
\hline uterine carcinosarcoma & UCS & 57 & 0 \\
\hline uveal melanoma & UVM & 80 & 0 \\
\hline & & & \\
\hline
\end{tabular}



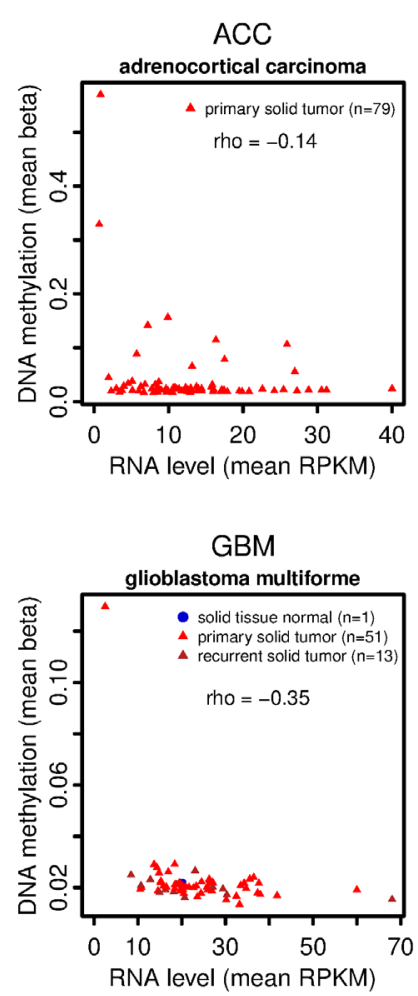

OV

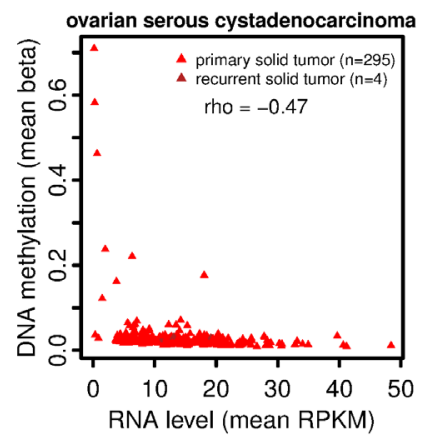

TGCT

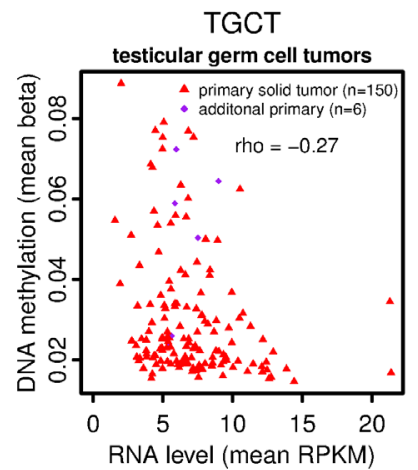

CESC

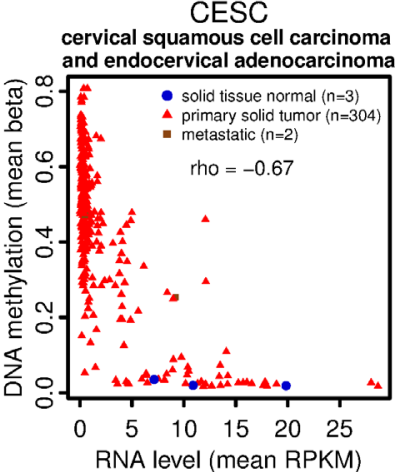

$\mathrm{KICH}$

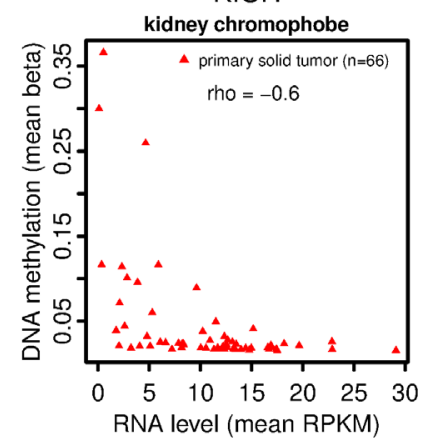

PCPG

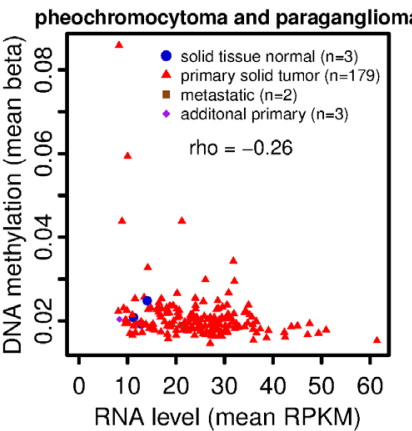

THYM

thymoma

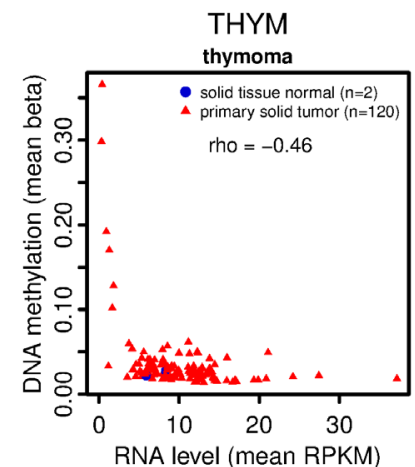

CHOL

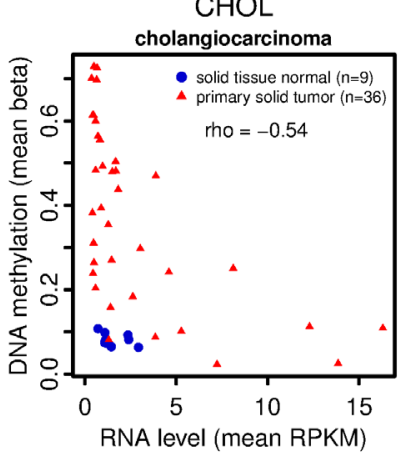

LGG

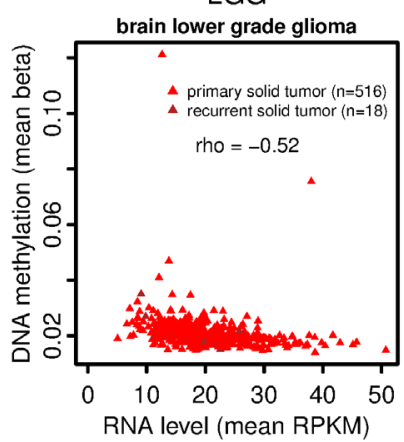

SARC

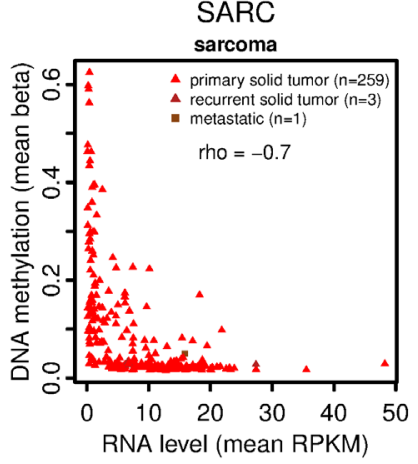

UCS

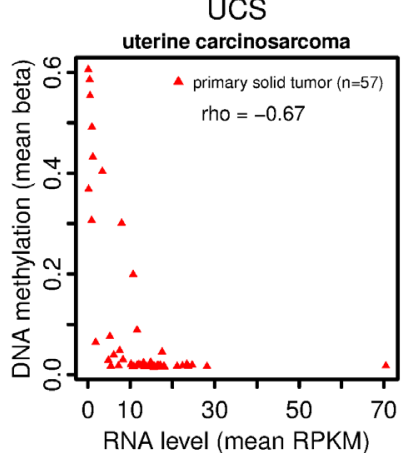

ESCA

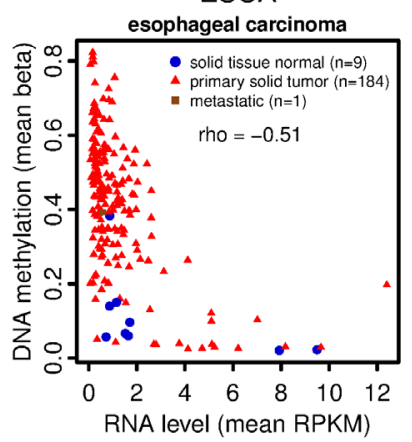

MESO

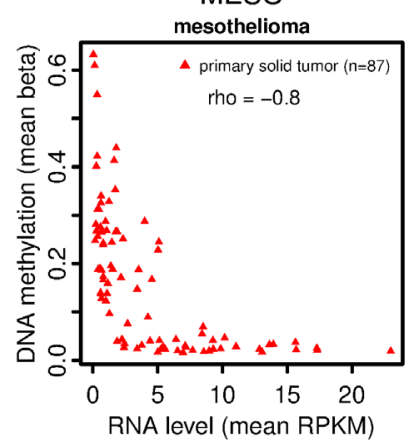

STAD

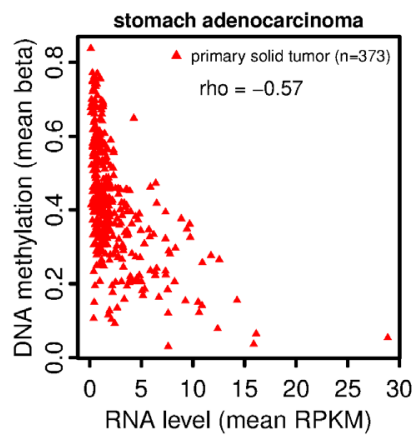

UVM

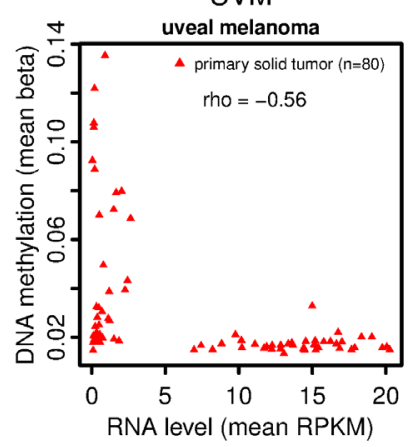

Figure 1. Integration of the MORT expression and the MORT promoter DNA methylation TCGA data for 16 tumor types. The X-axis shows the MORT expression level according to RNA-seq and y-axis shows the level of MORT promoter DNA methylation according to Illumina HumanMethylation450 microarray. The correlation coefficient rho between the MORT expression and the DNA methylation of MORT promoter for each tumor type is displayed. The OV has a very low number (10) of samples analyzed by the HumanMethylation450 platform, therefore the data from the HumanMethylation27 platform that covers $2 \mathrm{CpGs}$ out of $7 \mathrm{CpGs}$ covered by HumanMethylation450 were used. 
of MORT promoter in some of these cancers is either very low (UVM), or a very few tumor samples have MORT silenced (ACC, KICH, OV, and THYM), and some of the cancer types (GBM, LGG, PCPG, and TGCT) do not appear to display $M O R T$ gene silencing (Figure 1).

The analysis presented shows DNA methylation associated MORT gene silencing in 7 of 16 TCGA cancer types. Compared to the 17 TCGA cancer types presented in our original study, ${ }^{1}$ most the 16 cancer types presented here lack their respective normal tissues samples and some of them have lower amounts of tumor samples (Table 1). Nevertheless, the distribution of MORT expression and DNA methylation data in tumor samples clearly indicates MORT silencing in multiple cancer types (Figure 1).

Cervical tumors (CESC) have high proportion of MORT silencing (Figure 1); more than $75 \%$ of 304 cervical tumor samples have MORT promoter DNA hypermethylated and $M O R T$ silenced. Using TCGA data, a recent study found MORT downregulated in cervical cancer ${ }^{11}$, but surprisingly did not report on or hypothesize potential mechanisms for this transcriptional repression. Here we confirm and extend their initial analysis of MORT silencing in cervical cancer and show further that this silencing is strongly linked to aberrant DNA methylation of the MORT promoter.

Combined together with the findings from our previous report $^{1}$, Table 2 shows MORT is silenced by DNA methylation in

Table 2. Summary of MORT silencing in all 33 TCGA cancer types. The cancer types with MORT silencing in a large fraction of tumor samples are indicated. Results from this study are indicated $\left({ }^{*}\right)$, results from our previous report (ref 1 ) are indicated $(* *)$.

\begin{tabular}{|c|c|c|}
\hline Abbreviation & TCGA cancer type name & $\begin{array}{l}\text { MORT } \\
\text { silencing }\end{array}$ \\
\hline $\mathrm{ACC}$ & adrenocortical carcinoma & $\mathrm{No}^{*}$ \\
\hline BLCA & bladder urothelial carcinoma & Yes $^{\star *}$ \\
\hline BRCA & breast invasive carcinoma & Yes $^{* *}$ \\
\hline CESC & $\begin{array}{l}\text { cervical squamous cell carcinoma } \\
\text { and endocervical adenocarcinoma }\end{array}$ & Yes $^{*}$ \\
\hline $\mathrm{CHOL}$ & cholangiocarcinoma & Yes $^{*}$ \\
\hline COAD & colon adenocarcinoma & Yes $^{\star *}$ \\
\hline DLBC & $\begin{array}{l}\text { lymphoid neoplasm diffuse large } \\
\text { b-cell lymphoma }\end{array}$ & Yes $^{\star *}$ \\
\hline ESCA & esophageal carcinoma & Yes $^{*}$ \\
\hline GBM & glioblastoma multiforme & $\mathrm{No}^{*}$ \\
\hline HNSC & $\begin{array}{l}\text { head and neck squamous cell } \\
\text { carcinoma }\end{array}$ & Yes $^{* *}$ \\
\hline $\mathrm{KICH}$ & kidney chromophobe & $\mathrm{No}^{*}$ \\
\hline
\end{tabular}

\begin{tabular}{|c|c|c|}
\hline Abbreviation & TCGA cancer type name & $\begin{array}{l}\text { MORT } \\
\text { silencing }\end{array}$ \\
\hline $\mathrm{KIRC}$ & kidney renal clear cell carcinoma & Yes $^{\star *}$ \\
\hline KIRP & $\begin{array}{l}\text { kidney renal papillary cell } \\
\text { carcinoma }\end{array}$ & Yes $^{* *}$ \\
\hline LAML & acute myeloid leukemia & Yes $^{\star *}$ \\
\hline LGG & brain lower grade glioma & $\mathrm{No}^{*}$ \\
\hline LIHC & liver hepatocellular carcinoma & Yes $^{\star *}$ \\
\hline LUAD & lung adenocarcinoma & Yes $^{* *}$ \\
\hline LUSC & lung squamous cell carcinoma & Yes $^{\star *}$ \\
\hline MESO & mesothelioma & Yes* $^{*}$ \\
\hline OV & $\begin{array}{l}\text { ovarian serous } \\
\text { cystadenocarcinoma }\end{array}$ & $\mathrm{No}^{*}$ \\
\hline PAAD & pancreatic adenocarcinoma & Yes $^{\star *}$ \\
\hline PCPG & $\begin{array}{l}\text { pheochromocytoma and } \\
\text { paraganglioma }\end{array}$ & $\mathrm{No}^{*}$ \\
\hline PRAD & prostate adenocarcinoma & $\mathrm{No}^{* *}$ \\
\hline READ & rectum adenocarcinoma & Yes $^{\star *}$ \\
\hline SARC & sarcoma & Yes $^{*}$ \\
\hline SKCM & skin cutaneous melanoma & Yes $^{* *}$ \\
\hline STAD & stomach adenocarcinoma & Yes $^{*}$ \\
\hline TGCT & testicular germ cell tumors & $\mathrm{No}^{*}$ \\
\hline THCA & thyroid carcinoma & $\mathrm{No}^{* *}$ \\
\hline THYM & thymoma & $\mathrm{No}^{*}$ \\
\hline UCEC & $\begin{array}{l}\text { uterine corpus endometrial } \\
\text { carcinoma }\end{array}$ & Yes $^{\star *}$ \\
\hline UCS & uterine carcinosarcoma & Yes* $^{*}$ \\
\hline UVM & uveal melanoma & $\mathrm{No}^{*}$ \\
\hline
\end{tabular}

a super majority of TCGA cancer types (22 of 33). MORT loss occurs predominantly due to epigenetic silencing and increased DNA methylation of its promoter in breast cancer'. This could likely be extended to all 22 cancer types with the high fraction of MORT negative samples and the high correlation between $M O R T$ RNA level and MORT promoter DNA methylation, where MORT likely plays a tumor suppressive role. The other 11 cancer types, with a little to no MORT silencing, might have tumor suppressive pathway, where MORT is involved, interrupted elsewhere and/or MORT may play some additional vital role in tissues these tumors originate from - e.g. prostate, thyroid, brain, testes, or ovary - since these tissues typically have the highest levels of MORT RNA ${ }^{1}$.

In summary, our findings show that the MORT gene is one of the most common epigenetic aberrations seen in human cancer. Coupled together with MORT silencing occurring early in the 
temporal arc of human carcinogenesis it strongly supports a tumor suppressive role for MORT.

\section{Data availability}

Illumina HiSeq RNA-seq and HumanMethylation450 DNA methylation data for TCGA cancer types used in the present study can be downloaded from the GDC data portal.

\section{Competing interests}

No competing interests were disclosed.
Grant information

This work was supported by the Maynard Chair in Breast Cancer Epigenomics at the University of Arizona Cancer Center and the Cancer Center Support Grant (P30 CA023074).

The funders had no role in study design, data collection and analysis, decision to publish, or preparation of the manuscript.

\section{Acknowledgments}

The results shown here are based upon data generated by the TCGA Research Network: http://cancergenome.nih.gov/.
1. Vrba L, Garbe JC, Stampfer MR, et al: A lincRNA connected to cell mortality and epigenetically-silenced in most common human cancers. Epigenetics. 2015; 10(11): 1074-83.

PubMed Abstract | Publisher Full Text | Free Full Text

2. $\mathrm{NCl}$ NHGRI, NIH: The Cancer Genome Atlas. NIH, National Cancer Institute, National Human Genome Research Institute, 2016. Reference Source

3. Abba MC, Gong T, Lu Y, et al:: A Molecular Portrait of High-Grade Ductal Carcinoma In Situ. Cancer Res. 2015; 75(18): 3980-90. PubMed Abstract | Publisher Full Text | Free Full Text

4. Fleischer T, Frigessi A, Johnson KC, et al.: Genome-wide DNA methylation profiles in progression to in situ and invasive carcinoma of the breast with impact on gene transcription and prognosis. Genome Biol. 2014; 15(8): 435. PubMed Abstract | Publisher Full Text | Free Full Text

5. Johnson KC, Koestler DC, Fleischer T, et al.: DNA methylation in ductal carcinoma in situ related with future development of invasive breast cancer. Clin Epigenetics. 2015; 7: 75.

PubMed Abstract | Publisher Full Text | Free Full Text

6. Luo Y, Wong CJ, Kaz AM, et al.: Differences in DNA methylation signatures reveal multiple pathways of progression from adenoma to colorectal cancer.
Gastroenterology. 2014; 147(2): 418-29.e8. PubMed Abstract | Publisher Full Text | Free Full Text

7. Qu X, Sandmann T, Frierson $\mathrm{H} \mathrm{Jr}$, et al.: Integrated genomic analysis of colorectal cancer progression reveals activation of EGFR through demethylation of the EREG promoter. Oncogene. 2016; 35(50): 6403-6415. PubMed Abstract | Publisher Full Text | Free Full Text

8. Reyngold M, Turcan S, Giri D, et al.: Remodeling of the methylation landscape in breast cancer metastasis. PLoS One. 2014; 9(8): e103896. PubMed Abstract | Publisher Full Text | Free Full Text

9. Vrba L, Futscher BW: Epigenetic Silencing of MORT Is an Early Event in Cancer and Is Associated with Luminal, Receptor Positive Breast Tumor Subtypes. J Breast Cancer. 2017; 20(2): 198-202. PubMed Abstract | Publisher Full Text | Free Full Text

10. Team RC: R: A Language and Environment for Statistical Computing. Vienna, Austria: R Foundation for Statistical Computing, 2017 Reference Source

11. Zhao LP, Li RH, Han DM, et al:: Independent prognostic Factor of low-expressed LncRNA ZNF667-AS1 for cervical cancer and inhibitory function on the proliferation of cervical cancer. Eur Rev Med Pharmacol Sci. 2017; 21(23): 5353-60. PubMed Abstract | Publisher Full Text 


\section{Open Peer Review}

\section{Current Peer Review Status:}

\section{Version 1}

Reviewer Report 03 April 2018

https://doi.org/10.5256/f1000research.15158.r31592

(C) 2018 Dobrovic A. This is an open access peer review report distributed under the terms of the Creative Commons Attribution License, which permits unrestricted use, distribution, and reproduction in any medium, provided the original work is properly cited.

\section{Alexander Dobrovic \\ Translational Genomics and Epigenomics Laboratory, Olivia Newton-John Cancer Research Institute, Heidelberg, Victoria, Australia \\ This brief article provides an analysis of MORT epigenetic silencing across 16 TCGA tumour types not previously reported by the authors enabling assessment across all TCGA tumour types. MORT silencing seems to be a key early event in carcinogenesis. This indicates that further studies of MORT biology are required as well as investigation of MORT methylation as a potential biomarker. \\ Competing Interests: No competing interests were disclosed. \\ Reviewer Expertise: DNA methylation biomarkers, liquid biopsies, digital PCR \\ I confirm that I have read this submission and believe that I have an appropriate level of expertise to confirm that it is of an acceptable scientific standard.}

Reviewer Report 03 April 2018

https://doi.org/10.5256/f1000research.15158.r31980

(C) 2018 Lomberk G. This is an open access peer review report distributed under the terms of the Creative Commons Attribution License, which permits unrestricted use, distribution, and reproduction in any medium, provided the original work is properly cited.

\section{Gwen Lomberk}

Division of Research, Department of Surgery, Medical College of Wisconsin, Milwaukee, WI, USA

STRENGTHS: The authors utilize the TCGA database to extend their previous studies on MORT that has been primarily characterized in breast cancer, but also observed to undergo silencing in 15 out of the 17 most common cancers. The current work takes this analysis deeper into the 33 TCGA 
cancer types and perform a more thorough analysis of the DNA methylation associated with the 16 cancer types evaluated here.

\section{SUGGESTIONS FOR IMPROVEMENT:}

-The authors make a bold statement that "the MORT gene is one of the most common epigenetic aberrations seen in human cancer". This statement is not supported by the data presented. In order to make a statement of this level, the authors would have to provide comparisons to other documented genes that undergo a high frequency of epigenetic alteration.

-This statement becomes more difficult to make when considering that several of the tumors present do not have normal counterparts for comparison. We therefore do not know if those tissue types whether the DNA methylation is abnormal or typical for the tissue type.

-Authors should consider revising some of the scales on the graphs in Figure 1 to highlight the lack of methylation (for example, in testicular germ cell tumors). Similarly, the cutoff for methylation could be shown by a dotted line or similar feature.

-The location of methylation relative to the MORT gene would be informative. Of the tumor types that are methylated, are the same regions methylated across types?

-The authors should be cautious not to overstate their conclusions throughout the text since the conclusions are speculative without experiments to support their statements. Nevertheless, these correlations present interesting speculation and avenues for further investigations.

Competing Interests: No competing interests were disclosed.

I confirm that I have read this submission and believe that I have an appropriate level of expertise to confirm that it is of an acceptable scientific standard.

Reviewer Report 01 March 2018

https://doi.org/10.5256/f1000research.15158.r31096

(C) 2018 Karpf A. This is an open access peer review report distributed under the terms of the Creative Commons Attribution License, which permits unrestricted use, distribution, and reproduction in any medium, provided the original work is properly cited.

\section{Adam Karpf}

Eppley Institute and Fred \& Pamela Buffett Cancer Center, University of Nebraska Medical Center, Omaha, NE, USA

The authors present a straightforward study of DNA methylation and RNA expression of the InCRNA MORT in 16 TCGA cancer types not previously reported. Most of the paper is clearly presented and the conclusions are reasonable. Suggestions for improvement are presented below. 
1) Statements are made regarding MORT being "one of the most common" epigenetic aberrations seen in human cancer. No support for this statement is presented.

2) The classification of some tumor types as showing "strong" MORT silencing by DNA methylation, and other tumor types as not showing this, is arbitrary. A quantitative definition is needed.

3) Fig 1 might be clearer if presented in two panels, subdivided by whether the quantitative definition of "strong silencing" is met. The same is true for Table 2, which could be subdivided into two parts.

4) Since normal samples were not available for many of the tumors profiled, a more accurate statement might be "DNA methylation regulation" rather than "DNA methylation silencing," as reduced expression in tumors as compared to normal tissues was not shown.

5) A diagram showing the MORT gene and the position of the methylation sites examined by the TCGA would be helpful.

6) Can the authors reference any data, e.g. from other publications, showing that DNA methylation actively suppresses MORT expression, by for example turning on MORT expression using treatment with a DNA methyltransferase inhibitor?

7) In the introduction, the statement "prior to or at the stage of pre-malignancy and not thereafter" is confusing, and gives the impression that MORT becomes hypomethylated, or its expression is elevated, in tumors as compared to pre-malignant lesions. A better way to phrase this would be to say e.g. that "MORT is repressed in pre-malignant lesions and remains repressed in tumors."

8) The final sentence in the discussion uses the wording "strongly supports" when "suggests" would be more accurate, given the absence of functional data showing tumor suppression by MORT.

Competing Interests: No competing interests were disclosed.

I confirm that I have read this submission and believe that I have an appropriate level of expertise to confirm that it is of an acceptable scientific standard.

The benefits of publishing with F1000Research:

- Your article is published within days, with no editorial bias

- You can publish traditional articles, null/negative results, case reports, data notes and more

- The peer review process is transparent and collaborative

- Your article is indexed in PubMed after passing peer review

- Dedicated customer support at every stage

For pre-submission enquiries, contact research@f1000.com

F1000Research 